\title{
Research on the Construction of Modern Teachers' System in Practical Cooking Specialty
}

\author{
Lin Li \\ Jilin Agricultural Science and Technology university, Jilin 132101, China \\ email: ziyul11@sina.com
}

Keywords: application-based cooking, professional, modern mentoring system, construction

\begin{abstract}
At present, the role of "modern mentoring system" in promoting professional transformation and development has been widely recognized. And various professions are studying the "modern mentoring system" which is suitable for the specialty. Since the birth of the specialty, the application of "modern mentoring system" has to be transformed and developed. This article explores the establishment of the modern scholarly system of culinary specialty, and also finds some problems in using the method and puts forward their own solutions, hoping to inspire the peers.
\end{abstract}

\section{Introduction}

"Mentoring system" teaching model has a long history, in the long history of the river, the handicrafts are basically through the "mentoring system" teaching which is mode for personnel training and skills inheritance. It can be said that the "mentoring system" for the traditional hand skills transfer has great significance. Today, the "mentoring system" still has a huge role. But in the new era, it is given a new connotation, we call it "modern mentoring system."

\section{Modern Mentoring System}

Modern mentoring system and the traditional mentoring concept has inherited and developed, both contact, there are differences. In the current industrial production under the premise of the traditional mentoring concept of one-on-one teaching has been far from being able to meet the needs of a large number of people on the community. The traditional mentoring long teaching cycle is completely unable to adapt to the rapid development of modern society. Modern school education massly training ways to solve the problem of quantity, but its quality has been criticized for a long time, so that some enterprises in the new entry after spending a lot of manpower, material and financial resources to re-culture. It is not only a waste of business time and money, but also the waste of time for new workers. In this context, the modern apprenticeship comes into being and its core emphasizes "school-enterprise", "double teacher training", "engineering alternation", "post talent".

Modern mentoring system emphasizes the deep cooperation between school and enterprise, which can not simply understand for the enterprise to provide "cheap labor", but a cooperative type of personnel training model. It is not one-sided emphasis on practical ability, but a comprehensive talent way of training.

\section{Cooking Professional Modern Mentoring System Establishment}

Master Source. In the new mentoring relationship, the selection of "division" is very important, which is related to the success or failure of the whole system construction.

First, normal teachers are the primary source of "master", college teachers themselves are students of professional teachers, students have to follow the guidance of learning, he has a congenital mission responsibility, is the "master" doing my part. it is authoritative. University teachers themselves are experts in the field of identity, from the academic point of view of the authority; college teachers engaged in teaching students in the hearts of teachers to establish a 
prestige, from the perspective of teacher and student authority; there is a guide. From the perspective of discipline, the ability of university teachers' research ability and teaching and research ability to guide the direction of discipline; from the student's psychological point of view, it is more likely to cause students to rely on psychological, so that students have the ability to guide the psychological.it is enforceable. The training objectives of the school, the direction of training, the development of teaching programs, the results of teaching evaluation, etc., need teachers to train the program according to the personnel training program. There are plans, organized the development, and only teachers to complete this mission, for students to complete the training objectives to escort.

Second, the purpose of the new mentoring relationship is to get out of the school, to the enterprise learning, training enterprises need talent, from the enterprise selection of skilled staff as a master, is to allow students to learn from the practice of professional knowledge, practical practice practical ability. the technology is perfect. Enterprise front-line staff because of a long time in the first line of professional work, its technical level is often stronger than the university teachers, high level of proficiency, practical ability to deal with practical problems, to give students practical guidance in practice, improve students hands-on ability. the social strong. Business employees living in society, more able to teach students to teach the survival of the law, which is living in the ivory tower of the university teachers is difficult to do. strict management. Enterprise master will use the company's strict requirements of students, students will consciously use their own standards to ask themselves, which will get rid of some of the students lazy bad habits, cultivate a good quality of hard work and hard work.

Third, senior students are another source of master, selected junior students and freshman students to form a one-on-one mentoring relationship, both can play a high grade to help the role of lower grades, but also can supervise and supervise the senior students Self-learning, is a two-pronged move., it is easy to establish mentoring relationships. As the identity is close, are students, low-grade students are more likely to produce a dependency, convincing feeling, it is easier to establish a teacher and friends also close teacher relationship. it is easier to enter the professional role. Due to the guidance of senior students, junior students are more likely to deepen their understanding of the profession and reduce the possibility of detours. For the cooking and nutrition education, one of the professional direction is the culinary professional teachers, so the guidance and help of junior students can help students graduating from the professional sense of identity, but also a practice, Early entry into professional roles.

School-Enterprise Cooperation Model. Under the modern mentoring system, school-enterprise cooperation is no longer a simple level for enterprises to provide technical operation of workers. it requires schools and enterprises to a deeper level of integration, combined to co-develop students to meet the needs of the social needs of training Talent.

Under the guidance of this idea, schools and enterprises will jointly develop the "personnel training program", jointly proposed in line with the actual interests of both enterprises and the implementation of the program, jointly selected to cooperate with the development of specific personnel. School selected teachers to obey the rules and regulations of the enterprise, while the company selected the master to meet the corresponding requirements of the school to complete the school's indicators. In the training time and place, the two sides to study together to the most conducive to student learning as a prerequisite, you can choose the enterprise into the campus, students into the enterprise and school-run enterprises and so on.

First, enterprise into the campus. To the school funded the introduction of enterprises, so that enterprises in the school set up within the school "factory" [1], the corporate culture, enterprise production, business and other links into the campus, so that students in the "school factory" Business atmosphere, to become a member of the enterprise."School factory" has its unique advantages.

Second, according to the cooperation agreement between the school and the two sides, so that students to the enterprise internship, by the enterprise selected "master" for students to teach and unified management Students into the enterprise, more immersive feel the corporate culture, more 
access to the actual workplace, complete the "do secondary school" task.

Third, school-run enterprises are more favorable mode of cooperation between enterprises and enterprises, and Jilin Agricultural Science and Technology Institute of the hotel's specific cooperation process, found its advantages in the following areas. easier to supervise. Because the school-run enterprise is founded by the school, the purpose of the establishment is to serve the teaching. Therefore, the place for the students to practice the practice is its mission. Such enterprises, whether it is the management of the students or the choice of teaching contents, assign the "master" and so on Aspects, will be in accordance with the requirements of the school, easier to negotiate and supervision. the purpose of clear. School-run business purpose is very clear, that is, teaching services, students on the school-run enterprises to practice learning, and its training objectives are very clear, so that it can maximize the acceptance of student internship, provide "master" also has teaching The ability to meet the school requirements, save the time of retraining, improve work efficiency.

Adapt to the Teaching Model. "Modern mentoring system" Although the traditional mentoring system with the same strain, but its own characteristics, but also different from the current stage of the school teaching system, cooperative school model itself is more special, which requires a suitable teaching Match the pattern.

Optimize the Talent Training Program. Talent training program is the basis and basis for the training of personnel in the school. To realize the modern mentoring system, we must first adjust and optimize the personnel training program. The development of the professional personnel training program requires the participation of both enterprises and enterprises[2].To achieve the purpose of co-cultivation of school and enterprise and make effective adjustments to the teaching time. The number of teaching weeks at this stage is relatively fixed, the requirements are relatively strict, but in the implementation of the modern mentoring system teaching process, to break the teaching time and business time between the barriers is very important to make teaching time and business Working time docking. Cooking business users have a busy season of the points in the business season for students to enter the enterprise to learn more favorable, students are more exposed to the actual situation, companies are more willing to accept students, and employees in the off-season can let students in school Study professional courses, great savings in time costs, the completion of both school and school teaching.

\section{The Existence of the Problem}

First, the school long-term cooperation. School-enterprise cooperation is a prerequisite, that is consistent with the common interests of both sides. The operation of the enterprise is closely related to the market. The operating efficiency of the enterprise is directly affected by the cooperation between the school and the enterprise. The training period is a period of time, and the teaching period is at least three years. This will require the school enterprises to cooperate for a long time. if Enterprises only the pursuit of short-term benefits, long-term cooperation is difficult to achieve.

Second, re-practice light theory. In the original traditional teaching thinking, there is emphasis on the theory of light practice, in the modern system of mentoring system, this idea has been effectively resolved, the cultivation of practical ability to be mentioned to a higher height, but this long The practice mode of the enterprise practice will make the school, the teacher and the student produce a kind of thinking mode which emphasizes the theory of light theory, but this kind of thought is the same as the theory of light practice and is not conducive to the professional development of the students.

Third, master training. enterprises to provide the selected master in the technical level must be excellent, but because of the nature of their work, the need for teachers with education and teaching ability, but under normal circumstances, the enterprise selected master is not equipped with this ability, which requires schools to give some training in order to truly become a student "master", in line with school teaching requirements.

Fourth, school-enterprise cooperation, the students in the enterprise learning time, which is the school student supervise in the blind area, sometimes, beyond the reach of the school is bound to 
exist in the situation is not in place.

Fifth, school-enterprise cooperation, students need to travel between schools and enterprises, on the way back and forth, there will be traffic safety risks. At the same time, the students work in the enterprise, so there will be security risks.

Sixth, teaching time adjustment problem. The break of the teaching week will also break the original plan of teachers 'teaching. Breaking in the systematic arrangement of the theory teaching, which makes the theory compressed or intermitted. It will not only bring influence to the teaching management, but also bring influence to the students' study.

\section{The Problem Solution}

First, school-enterprise cooperation is a long-term cooperative relationship, not only the immediate interests of the school in the choice of enterprises should pay attention to preferred choice, which are not choosing the economic strength of better enterprises, choosing credibility and efficiency are better business, and choosing to pay attention to personnel training enterprises, but also pay attention to select the staff have better development of space business.

Second, do a good job in training and education. To the enterprise selected "master", to strengthen its education and teaching ability training, so as soon as possible to become a qualified with teaching and learning ability "teacher". Teachers of the school are to strengthen the technical capacity of the training. Since the "master", we must charge the technology clearance, in order to have a "double teachers" ability. Not only for students, but also on the "master" to carry out long-term education, and not only pay attention to theory or only pay attention to practice, for a comprehensive high-quality professionals. The theory and practice are equally important. Without practice, the theory is on paper, and without theory, practice is the air castle, so the two equally are important. We can not underestimate any side.

Third, select the teacher led to the enterprise to practice teaching, to complete the school students within the enterprise supervision of the work. At the same time, requiring enterprises to strengthen supervision of students, both schools and enterprises to work together to allow students to work more in place.

Fourth, teaching time fragmentation management. In the information age. In fact, the break of the teaching week can be used to solve the information which can not complete the school teaching, or using the information means to complete the knowledge points with micro classes. Mu class information means to complete teaching, so that modern means of information and modern mentoring system effectively combined, the maximum extent to ensure the implementation of teaching, and personnel training.

\section{Conclusion}

For the application of professional transformation, the modern mentoring system is undoubtedly a very worthwhile way of reform, cooking professional itself is very prominent application of its traditional teaching methods to the traditional mentoring system. So the application of modern division is very appropriate to reform the system. In this system, although the need to solve the problem more, after trying to solve the practice proves that this method is scientific and effective, which is suitable for this professional development.

\section{Acknowledgements}

In this paper ,the research by Jilin Education Department, 2016, key research topic of vocational education and adult education reform, project approval number: 2016ZCZ017: Modern mentoring system construction to promote the development of applied cuisine specialty. 


\section{References}

[1] Wang Ganlin, Huyu. Analysis on the Mechanism and Effect of Modern Physicians' System in the Environment of Enterprise [J]. Journal of Changjiang Engineering Vocational College. December 2015

[2] Liu Yang Wang, Hong Mei. Modern mentoring system of higher vocational teaching model research [J]. Technology Information .2016

[3] Li Jiangli. Vocational education "modern mentoring system" four training model [J]. Economist. 2013 No. 2: 141

[4] Li Tongguo. Based on the combination of work and study mentoring system teaching mode of integrated use [J]. Vocational Education Forum. April 2010

[5] Zhang Zhengtang, Jin Lan, Liu Ying. Improve the tutor system to promote the socialization of new employees [J]. China Human Resources Development. 2008 (04)

[6] LU Yan, LIANG Liang. Study on tacit knowledge sharing by mentoring system [J] .Journal of Scientific Research Management 2008 (05)

[7] $\mathrm{Wu}$ Dongsheng. Enterprise training to restore the mentoring system [J]. Human resources development. 2005 (08) 